\title{
Cultural Language Learning Approach (CLLA): An Approach for Learners' Integrated Language Use Acculturation
}

\author{
Hermayawati \\ Universitas Mercu Buana Yogyakarta, Indonesia \\ https://orcid.org/0000-0003-2860-6322
}

\begin{abstract}
The current development of English Language Teaching (ELT) is gradually shifting towards learning language skills in an integrated manner that do not use separated skills. It makes teachers look for the right approach to teach the desegregated four language skills. Accordingly, this project investigated the Students of Candidate English Teachers (SCET) learning process using the Cultural Language Learning Approach (CLLA) for acculturating their Integrated Language Learning (ILL) in use. It was an applied study involving 100 SCET consisting of 60 females and 40 males aged between 20-22 years. They were intervened purposely in the learning process, to be well-acculturated to guard their native cultures. Quasi-semester meetings were carried out online. A closed-questionnaire and in-depth observation were the data gathering tools employed in this study. The results were analyzed descriptively using learners' engagement factors inspired by Lee, Song and Hong's model and Sheppard's scoring rubrics. The results revealed that $68.31 \%$ of learners were engaged during their ILL process. Besides, in-depth observation achieved the same average score, namely 77 in each quasisemester. Such scores were respectively categorized both in their learning engagement and achievement. Thus, CLLA can be used as an alternative approach to familiarize SCET with integrated language use in acculturating their ILL process. This study recommended further research on learners' ILL acculturation through different native cultures acculturation.
\end{abstract}

Keywords: approach; candidate English teachers; Integrated Language Learning; scoring rubrics; in-depth observation

\section{Introduction}

The demand for a "liberated learning" implementation model, that is launched by Indonesian's Ministry of Education and Culture, has been currently arousing the ELT (English Language Teaching) teachers to find novel alternative breakthroughs in their teaching manner. In line with such a demand, the development of technology has been affecting many aspects of human life 
mainly in English Language Teaching (ELT) which was previously taught in an isolated manner. To put it differently, in its beginning ELT received a number of approaches recommended by the linguists of the 20th-century concepts such as Grammar Translation Method (GTM), Audiolingual Method/Direct Method (AM/DM), Structural Approach, Oral Approach or Situational Language Teaching, Total Physical Response (TPR), Silent Way, Community Language Learning, Suggestopedia, Whole Language, Multiple Intelligence, Neurolinguistics Programming, the Lexical Approach, Competency-Based Language Teaching, Communicative Language Teaching (CLT), Natural Language Approach (NLA), and Task-based Language Teaching (TBLT), Cooperative Language Learning, Content-Based Instruction, and The post-methods era (Richards \& Rodgers, 2001; Tomlinson, 2001, Brown, 2007). Such approaches and methods were well-known and consistently used to teach foreign languages worldwide, however not all of them are used in Indonesia, particularly the CLLA which can be used to cultivate learners ILL practically.

In facts, the current development of the era, which generates the emergence of various new approaches or methods, pronounced the aforementioned approaches to become fade-away and less-popular except for the Communicative Language Teaching (CLT), Co-operative Language Learning (CLL), Total Physical Response (TPR) and Task-Based Language Teaching (TBLT) since they are popular and used by English teachers in Indonesia. It is important to mention that by the early $21^{\text {st }}$ century, various new approaches such as Contextual Teaching and Learning (CTL), Quantum Learning Method (QLM), Computer Assisted Language Learning (CALL), Content and Language Integrated Learning (CLIL), Multicultural Language Approach (MLA), Blended Learning Method (BLM) have been nowadays currently more popular and used to teach during the $21^{\text {st }}$ century. In this case, Waters (2012) suggests that methodology at the 'grass-roots' level has remained relatively stable over the last 15 years and continually updated in the forthcoming years by the growing use of electronic technology in language teaching.

By the existence of those methods and approaches, teachers have a various choice in their teaching, even they may also mix approaches together. Since the present paper is not concerned with any of these methods and approaches, yet CTL and BLM are of no exception as they were related to the Cultural Language Learning Approach (CLLA) employed to investigate in this research paper.

\section{Literature Review}

Contextual Teaching and Learning (CTL) was found by Johnson, Ida and Ibnu in 2007, in which teaching will be only effective when the content relates to the learners' real-life (Johnson, Ida \& Ibnu, 2007). In this case, the learning content is delivered in the discourse connected to the learners' daily life. In ELT practices, CTL can be actualized by providing learners with various appropriate texts according to their age (English for kids, young learners, adults) and level (beginners, false-beginners, intermediate, advanced, and professional) (Bailey, 2005). The term BLM (Blended Learning) was primarily introduced by Stein and Graham in their Book written in 2014 and then published in 2017 through 
European Journal and Education Studies. They defined that the BLM may be used to cultivate both onside and online assessments by which it enables the teacher to determine an assessment model that matches with the decided learning outcomes (Stein \& Graham, 2014). They also added that assessments do not just measure, but also provide learners' feedback that should be directly delivered by the teacher soon after the assessment according to be useful for them to improve their further learning.

Another relatively current novel approach related to CTL and BLM is Cultural Language Learning Approach (CLLA). It is an approach to teach language by employing traditional cultural heritages in which materials are presented in the form of texts (Setiadi, 2017). It was introduced by Hermayawati at the Oman 14th International ELT Conference hosted by SQU (Sultan Qaboos University) on 8th to 9th May 2014 in Muscat, Oman. The approach is intended to introduce the traditional cultural heritages that are being the future generation's responsibility to preserve and to have a sense of belonging towards their ancestors' valuable artifact, and to avoid getting fade away. So far, CLLA has been developed in ELT through human puppets performances that can be picked from YouTube as the teaching materials delivered in an integrated way by developing pairs-skills of listening-speaking and reading-writing (Hermayawati, 2020).

Actually, teaching the four language skills in unity has been suggested for more than six decades now , and research and practice in ELT have identified the four skills (listening, speaking, reading, writing) as paramount which in turn affected text-books and curriculum designing (Brown, 2007). Nevertheless, early observations showed that most ELT teachers in Indonesia still focus on their teaching in an isolated way, surprisingly in the last decade, they have been taught in an integrated manner to Students of Candidate English Teacher (SCET). However, ELT still has been delivered through two integrated pairs of listeningspeaking and reading-writing skills, due to the effect of curriculum development. Integrated Language Learning (ILL) pedagogical paradigms started to emerge into practice as the effect of the communicative language learning paradigm (Gautam, 2019; Tajzad \& Ostovar-Namagi, 2014), which was popular since two decades ago.

Regarding ILL, Brown (2007) suggested two previous language learning models, namely: content-based instruction (content-centred) and task-based instruction (CBI and TBI). CBI practically involves learners' activities to read, discuss, solve problems, analyze data, and write opinions and reports. TBI implies ILL in its focus on language in the real world mainly for functional purposes. CBI focuses on subject matter content, while TBI focuses on the whole set of real-world tasks. Besides, he also considered the use of Theme-based Instruction and Experiential Learning models. Those two models are proposed since most current ELT pedagogical materials (such as textbooks) and the authentic materials (such as teachers' hand-outs) have been used as ELT materials for intermediate and advanced learners. They are delivered thematically or topically in which 
learning activities need ILL for the sake of cultivating learners language learning experiences.

It is wiser the record that the English language enjoys the status of a foreign language and not as a second language (ESL) since it has its second language, namely, Bahasa Indonesia. It has various unique cultures, including the dominant ethnic, Javanese. Based on the ethnic classification, there are approximately $40 \%$ of Javanese where the total population concentrated on the island of Java (Yuniari, 2016; Leinbah, 2020). Thus, Javanese culture is used as the focus of CLLA study for the ILL approach. In this study, ILL involves desegregated four language skills focusing on both the learners' linguistic acquisition and the new knowledge embedded in the learned materials.

This study is addressed to acculturate the students of candidate English teachers (SCET) ILL acculturation using CLLA wherein the latter is as an approach with Javanese cultural heritages as the learning discourses. The previous studies have not found the ILL process involving the four language skills (listening-speakingreading-writing) in desegregating use. It might be because of the current existing ELT curricula that have not put the four ILL as a unity nor contextually. This study also purposefully introduced CLLA as a novel approach that has not been well-acknowledged by the relevant teachers thought it is considered as an appropriate approach to introduce and preserve traditional cultures to develop learners ILL through the learning process acculturation. Based on the above considerations, there were two under-observed variables, namely the acculturation of CLLA and SCET's ILL in the use process.

\subsection{Acculturating Learners' Integrated Language Use Using CLLA}

By definition, acculturation is a process of acquiring certain cultural aspects of a dominant culture by the non-cultural members (Berry, 2003). Marsiglia et al. (2011) reported that universal prevention interventions for the minor ethnic need to adapt to their linguistic acculturation trajectories. It can be triggered by intercultural contact, which may affect attitudes, norms, behaviours, knowledge, and identity changes (Berry, 2007). The above findings implied that acculturating a certain dominant culture can be well-acquired by the other nondominant cultures. Hence, this study cultivated Javanese cultural heritages as the dominant culture to intervene in the ILL of the non-dominant cultures that joined the ELT courses. As an illustration, Figure 1 provides the research paradigm of this study. 


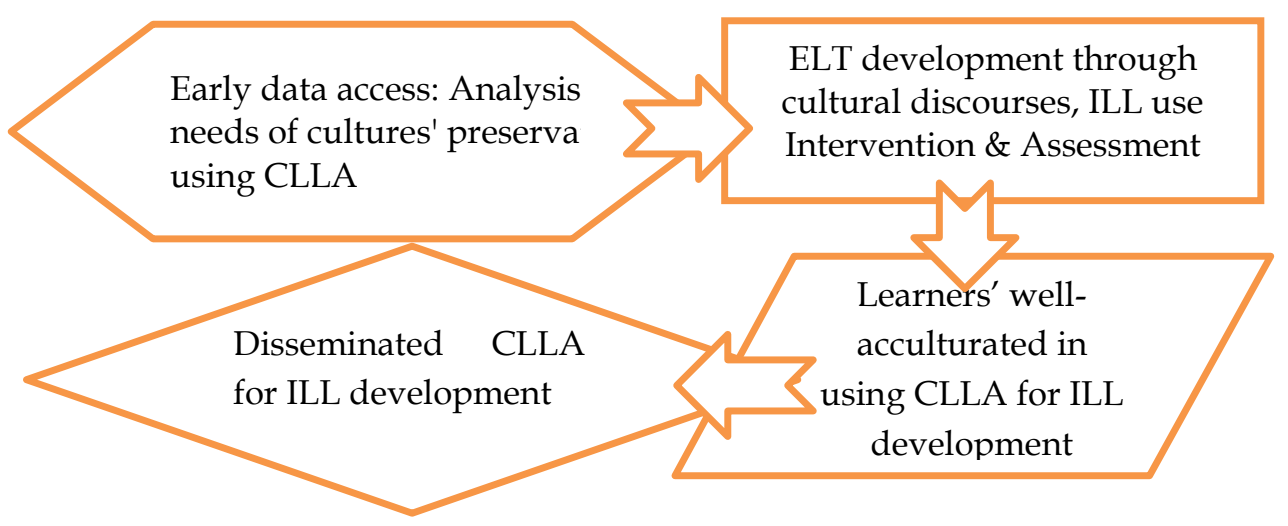

Figure 1: The Research paradigm

Figure 1 shows the research paradigm that starts from accessing the research problems, namely the needs for cultural heritage preservation through ILL development using CLLA acculturation. By doing so, ILL which is (in this case) conducted in ELT intervention by employing CLLA can be developed and disseminated. Acculturation and dissemination processes are used as an attempt to preserve cultural heritage.

Several types of Javanese culture heritages may be used as learning materials. They are, among others, in the forms of building, art performance, songs, foods, ceremonies, kinds of music, legends, folklore, clothing and heirlooms. Among those heritages, one may mention "wayang" (human and leather puppets), "batik" (a name of especially Javanese fashionable clothing), "reyog" (traditional art performance), "keris" or "kris" (a traditional Javanese heirloom) which have been recognized by UNESCO (United Nations of Educational, Scientific, and Cultural Organization) as the world's cultural heritages since 2003 (UNESCO, 2020). When investigating "wayang orang" or human puppets (HP) stories as the learning media, results revealed that HP can be benefited as learning materials for they contained hidden messages with moral values. More significantly, it can be used as a media for embedding learners' ILL. Nevertheless, HP had not been used as learning materials in ELT in Indonesia. Wayang stories are not only useful as an introduction to new knowledge, but also as a medium of entertainment and for moral education (Suyanto, 2013; Marsaid, 2016; Purwanto, 2018). Another study focused on Mahabharata and the Ramayana by looking at their benefits. All stories were originally performed in the Javanese language but completed with the Indonesian language subtitles in every story. The learners' tasks were respectively watching, understanding, rewriting and peers' assessing the group stories' synopses written in English in which the main intention was to acculturate learners' meta-cognitive dimension.

In contrast to the author's previous studies, this study examined the different types of traditional Javanese cultural heritage, primarily addressed to the Javanese traditional "building" and "traditional ceremony". The benefited building types included "Joglo House", "Kraton", "Benteng Vredeburg" or "Vredeburg Fort" (as the Dutch colonial heritage) and "Sonobudoyo Museum" (a museum of cultural heritage storage). Whereas, traditional ceremonies covered 
"Mitoni", "Tedhak Siten" and "Ruwatan". "Mitoni", "Tedhak Siten", "Ruwatan" and "Labuhan" which are still popular today, especially by people with middle and upper economic status, just as an effort to preserve them in Indonesia.

"Mitoni" is a ceremony especially addressed to a woman who is pregnant for seven months. She should be ceremonially performed for the sake of her own and her baby's safeness. "Tedhak Siten" is a ceremonial performance to train the first stepping down a baby on the ground when starting to walk. "Labuhan" is one of the Javanese traditional ceremonies commonly done by Kraton (Sultanate relatives) by carrying out food and clothes that are neatly made and arranged in a mountain-like shape as an expression of gratitude for all God gifts. The two types of heritages were employed both as the knowledge content (such as listening-speaking-reading-writing) and its linguistic aspects (such as sentence structure, grammar, vocabulary, pronunciation, spelling and comprehension).

\section{Methodology}

The present research paper used applied study as a type of research to find the specific solution of individuals, organizations, and industries (Baimyrzaeva, 2018). In this type of research, the researcher regulates environmental variables to minimize excessive behaviour or to increase deficits and evaluates the results using a combination of single-subject experimental designs and social validation tools (Jessel, 2020). Newton-Rex (2019) proposed six principles to be employed in an applied study. First, it ensures a clear and agreed-on product aim. Second, it involves the product in setting research objectives. Third, it estimates the length of the study. Fourth, it lets researchers choose their methods. Fifth, it has regular reviews of progress and considers whether to continue the work at each review. Sixth, it rewards good choices and speed to conclusions.

Accordingly, this study performed to gain the specific solution of the current issues concerning the cultural heritages that have been worried to be fade away extinct and need preservation, besides they can be very useful materials to develop Learners' ILL. It purposely investigated two observable variables, namely the use of CLLA (which functioned as the learning approach) and the ILL intervention process by involving two classes with different courses.

\subsection{The Participants}

Because the current paper aimed to address a critical point, it is crucial to care about the participants by defining important characteristics for data validity and reliability. Therefore, Students of Candidate English Teachers (SCETs) are the research informants in this study. They are selected because they enjoy a certain age and are adult learners with an advanced level of study. They are generally autonomous, goal-oriented, practical, competent and mastery, learning by experience, knowledgeable, purposeful, have emotional barriers, result-oriented, outside responsibilities, potential physical limitations, the big picture, selfresponsible, and need for community (Ann \& Strong, 2002; Malamed, 2009; Makhlouf, 2019). Considering such specified characteristics, they should be treated using andragogy, that is, a study of adult learning proposed by Knowles in 1950. 
Andragogy is principally used to teach adult learners who need to be treated as follows: (1) being involved in their instruction; (2) doing trial and error in their learning activities; (3) learning should be related to their personal real-life; (4) learning should be directed to problem-solving rather than the content-oriented (Knowles, 1984; Culatta, 2020). In a nutshell, it is practically instructed to more focus on the process rather than on the content being learned. Furthermore, Malcolm (1984) proposed 7 (seven) points of adult learning outcomes by enabling them to (1) acquire their understanding maturity; (2) respect toward others; (3) develop a life dynamic attitude; (4) learn to react to the causes, not the symptoms, of behaviour; (5) acquire the skills of their personalities potentials; (6) understand the essential values in human capital experience; and (7) understand their society to be skilful in directing social change. All of the above principles were considered as the basis of the participants' language learning process in integrated use, both receptively (in listening and reading activities) and productively (in speaking and writing activities).

Based on the above highlighted, 100 students of candidate English teachers (SCET) were research participants aged between 20 to 22 consisting of 60 females and 40 males who were purposely involved in the research project (Purposive sampling). They were intervened by purpose in the learning process, namely to be well-acculturated to guard and/or preserve their native cultures. 50 of them joined writing in a professional context course, and the rest joined the Materials and Media Designs (MMD) course. They were all categorized into adult learners and treated as pre-advanced English capacities. The two different classes were taken as research participants with the same intervention since they have similar needs in using practical ILL. Besides, they were all approached as the future teachers and the young generations all at once who have the responsibility in developing both ELT quality and cultural heritage preservation.

\subsection{Research Instruments}

In this study, CLLA which was the product of the author's previous research was employed as an approach within the SCET's ILL process for a semester. It was considered as the most appropriate approach to fulfill the needs of cultural heritage preservation efforts through the SCET's ILL. It was employed as an approach to acculturate the SCET's ILL process mixed with the BLM. A closedquestionnaire was distributed to gather learners' needs analyses as qualitative data. The in-depth observation was carried out during the learning process to gather quantitative data. The latter were collected by analyzing the gain score of the mid-term and the final tests achievements of the learners. Both data types were analyzed descriptively through (respectively) theoretical tree-angulation (data validation by comparing the data to the relevant theories) and the SCET's ILL test results assessment using Sheppard's (2015) scoring rubric.

Table 1 provides the example of using such scoring rubric that includes 7 assessment aspects, namely "overall impact", "clarity", "organization", "mechanic", "grammar", "style", and "presentation". Each aspect can be scored into 5 levels or categories of scores, namely "not yet" (1-2), "emerging" (3-4), "developing" (5-6), "effective" (7-8) and "strong" (9-10) with numerical scores 
spread from 1 as the lowest score until 10 as the highest score. The test taker will have completed a 70 score with the strong level category whenever s/he achieves a 10 point for the seven assessment aspects. Vice versa, s/he will get a 7 point when getting the lowest score at all of the 7 aspects being assessed. In other words, the total score spreads from 7 to 70 or from "not yet' to "strong" level category. A test-taker will achieve a score of 7 with "not yet" category level, if s/he gets 1 for all assessment aspects and will get "strong" when s/he gets score 70 for all assessment aspects. Table 1 illustrates a sample of a test taker who gets a total score of 65.7. It includes "effective" level for having: 6 for each in his "clarity", "organization" and "mechanic" aspects, and score 7 for each "overall impact", "grammar", "style" and "presentation" aspects.

Table 1: Sample of a test-taker achievement inspired by Sheppard's scoring rubric

\begin{tabular}{|l|l|l|l|l|l|l|}
\hline $\begin{array}{l}\text { Assessment } \\
\text { Aspects }\end{array}$ & $\begin{array}{l}\text { Not Yet } \\
1-2\end{array}$ & $\begin{array}{l}\text { Emerging } \\
\text { Overall }\end{array}$ & $\begin{array}{l}\text { Developing } \\
5-6\end{array}$ & $\begin{array}{l}\text { Effective } \\
7-8\end{array}$ & $\begin{array}{l}\text { Strong } \\
9-10\end{array}$ & Total \\
\hline Impact & & & 7 & & 7 \\
\hline Clarity & & & 6 & & & 6 \\
\hline Organization & & & 6 & & & 6 \\
\hline Mechanic & & & 6 & & & 6 \\
\hline Grammar & & & & 7 & & 7 \\
\hline Style & & & 7 & & 7 \\
\hline Presentation & & & & 7 & & 7 \\
\hline$\Sigma$ & & 18 & 28 & & 46 \\
\hline Comment & $46 / 70 \times 100=65.7$ & & & & \\
\hline
\end{tabular}

In connection with this study, the tests were assigned in groups of 5 , so that there were 20 groups involved in this study. Results of all the test-takers with the use of ILL were computed using the Mean Difference $\left(\mathrm{M}_{\mathrm{d}}\right)$ formula to find the gain score between the first (mid-term) and the second (final) tests. The following was the formula used to compute the $M_{d}$ that shows the numerical or coefficient number of the gain score. The higher the coefficient number is, the more significant the students' well-acculturated (in their ILL process using CLLA) will be.

$$
\mathrm{Md}=\Sigma \mathrm{X}_{1} / \mathrm{n}_{1}-\Sigma \mathrm{X}_{2} / \mathrm{n}_{2} \text { or } \mathrm{Md}=\bar{X}_{1}-\bar{X}_{2}
$$

Notes:

Md is Mean Difference;

$\Sigma \mathrm{X}_{1}$ is the total scores of Mid-term test takers;

$\Sigma \mathrm{X}_{2}$ is the total scores of Final-test takers; 
$\mathrm{n}_{1}$ is the number of Mid-term tests;
$\mathrm{n}_{2}$ is the number of Final-test takers;
$\bar{X}_{1}=$ The average number of Mid-term test;
$\bar{X}_{2}=$ The average number of Final-test takers.

\section{Findings}

As stated above, this study aimed at acculturating SCET's learning process by benefiting CLLA as an alternative approach to preserve the existence of Javanese cultural heritages as the most dominant ethnic in Indonesia. This section presents the results of the two prior under-observed variables, namely the acculturation of CLLA materials types and SCET's ILL in the use process. The followings are the details of the findings.

\subsection{Students' Engagement in the Online Learning Environment Using CLLA}

This study employed CLLA as an approach for the SCET's learning intervention with traditional culture buildings and ceremonies as the knowledge content. Seven types of Javanese cultural heritages were employed as the learners' learning materials namely "Joglo House", "Kraton", "Benteng Vredeburg" or "Vredeburg Fort" (as the Dutch colonial heritage) and "Sonobudoyo Museum" (a museum of cultural heritage storage) as the building types. The included "traditional ceremonies" were "Mitoni", "Tedhak Siten", "Ruwatan" and "Labuhan". Those seven material topics were delivered using the FUN procedure. FUN stands for "Finding (materials)", "Understanding (the target content)", and "Naturally- discussion". The FUN stages assigned the learners to cope with all activities that were carried out in groups of 5 for each class. There were 20 (groups) in two classes.

The "Finding (materials)" stage included the learners' involvement in finding their materials. Such an activity was purposely designed to activate the learners' creativity in selecting qualified discourse both in written and oral language. The "Understanding (the target content)" stage, included the learners' comprehensions towards the materials they have found through the discussion forum among their groups. The intention is to acculturate them to work together along with preventing them from being selfish. The "Natural-discussion" stage called learners to problems solving activities regarding the difficulties found during their discussion process. This activity aimed at acculturating them to solve their difficulties either individually or in groups. The final work of each group was in the form of written English text which was then, exchanged to other group's work to assess both its content and the language use. The groups' written language use was scored by using the scoring rubric, as previously highlighted (See Table 1). 
Table 2: The FUN stages of CLLA implementation

\begin{tabular}{|l|l|l|}
\hline Learning Stages Using CLLA & $\begin{array}{l}\text { Building } \\
\text { Types }\end{array}$ & Ceremony Types \\
\hline FUN $\begin{array}{l}\text { Finding (materials) } \\
\begin{array}{l}\text { Understanding (the target } \\
\text { content) }\end{array}\end{array}$ \\
\begin{tabular}{l} 
Naturally-discussion \\
\cline { 2 - 3 }
\end{tabular} & Kraton House & Mitoni \\
\cline { 2 - 3 } & $\begin{array}{l}\text { Benteng } \\
\text { Vredeburg }\end{array}$ & Ruwatan \\
\cline { 2 - 3 } & $\begin{array}{l}\text { Sonobudoyo } \\
\text { Museum }\end{array}$ & Labuhan \\
\hline
\end{tabular}

Regarding the in-depth observation that was carried out during the process of learning, findings revealed that CLLA was appropriately used to enable learners to be well-acquired both in understanding the given materials and in using the target desegregated language use. Such an observation was attentively conducted for seven virtual meetings during the learning process intervention. All of the learning processes were tested and scores were given for each group . The observation activities focused on the participants' ILL practice progress using CLLA. The ILL was delivered together within the use of such an approach. In this case, ILL functioned as an aggregate to comprehend the content of the materials being learned. The materials main topics were as follows: "building" and "traditional ceremony" with "Joglo House", "Kraton", "Benteng Vredeburg" (Vredeburg Fort), "Sonobudoyo Museum", "Mitoni", "Tedhak Siten", "Ruwatan" and "Labuhan" as the sub-topics. Table 2 illustrates the FUN stages of CLLA implementation.

All of the eight subtopics shown in Table 2 were assigned in 20 groups of 5 members who were not all Javanese. There were around 40 participants who were native Javanese, and the rest came from various other ethnics with different cultures spread in many other Indonesian islands. They come to Yogyakarta to study, as it is an education city centre located on Java island, the most populated city in Indonesia. Even though they come from non-dominant ethnics, they were enthusiastically involved in the learning process. Their learning engagement was observed from their activities, mainly as they performed groups discussion through virtual courses using G-meet-links.

Regarding learners' engagement measurement, this study was inspired by Dixon's (2015) and Lee et al. (2019) who asserted that learning engagement emerges by considering six factors, namely: psychological motivation, peer collaboration, cognitive problem solving, interaction with instructors, community support and learning management. Lee et al. (2019) proposed a 25item scale to improve student engagement. Such six factors, including the scale of the items, were considered for measuring the learners' learning engagement. They include "psychological motivation (consists of 6 items)", "peer collaboration (consists of 5 items)", "cognitive problem solving (consists of 5 items)", 
"interactions with instructors (consists of 2 items)", "community support (consists of 3 items)" and "learning management (consists of 4 items)". The followings are the details of six factors with each item categories.

Firstly, "psychological motivation" includes six items that are: interest enhancement in their virtual classes learning, motivation to study when taking virtual classes, feeling of usefulness to take virtual classes, interest to take the online course, looking forward to the next virtual meeting, after taking an online lesson, and Learners' satisfaction with the online class they are taking. Secondly, "peer collaboration" includes five items: study the lesson contents with other students, efforts to solve difficult problems with other learners when encountering them, working with other learners on online projects or assignments, efforts to ask other learners for help when they cannot understand the concept taught in the online classes, responses to answer the other students' questions. Third, "cognitive problem solving" consists of five items, namely: deriving new interpretations and ideas from the knowledge they have learned in the online classes, ability to analyze thoughts, experiences, and theories about the knowledge they have learned in the online course, ability to judge the value of the information related to the knowledge learned in the online classes, the tendency to apply the knowledge they have learned in the online course to real problems or new situations, efforts to approach the subject of the online course with other new perspectives.

Fourth, "interactions with instructors" consists of two items;: communication with the instructor privately for extra help and the frequency to ask the instructor concerning the course content. Fifth, "community support" consists of three items, including: feeling a connection with the other learners in the online classes, feeling a sense of belonging to the online class community and frequent interaction with other learners in the online course. Sixth, "learning management" consists of four items: study-related learning contents by themselves after the online lesson, tendency to remove all distracting environmental factors when taking the online course, management of their learning using the online system, and their necessities to plan a learning schedule when joining an online class.

All six factors, which include 25 engagement items, were delivered through the closed-questionnaire to collect data on the learners' engagement in the virtual learning environment using CLLA. A hundred learners were assigned to fill out the online questionnaire after completing a semester of the virtual meeting courses, conducted within 14 (meetings) through G-meet links. Data analysis yielded that $68.31 \%$ (of a hundred participants) were engaged with online learning using CLLA, while the rests $(31.69 \%)$ were not. This fact was primarily as the effect of their psychological motivation which shows that $52.22 \%$ were psychologically not engaged during their online course. This was not because of the use of CLLA, rather it was the effect of the online system they commonly underwent, by the time they joined the G-meet links to participate in the virtual courses. Most learners also complained about the affordability and interference 
of the internet signal during lectures, especially for students living in remote areas.

Such conditions were known when the lecture was taking place, as they had tried to join the link but failed and finally took part in the course via the chat application available on G-meet. On the positive side, learners who got problems with the internet network were still trying to attend lectures, which were indicated by the relatively high percentage of the three other observable aspects, namely "peers collaboration", "interaction with instructors" and "learning management" that reached above $81.84 \%, 72.35 \%$, and $79.22 \%$. Table 3 provides the learners' engagement in the virtual learning environment using CLLA. The other aspects of engagement, such as the "cognitive problem solving" and the "community support" were respectively achieved with $69.24 \%$ and $59.47 \%$. It means that there was $30.76 \%$ and $40.53 \%$ of learners got problems in such two aspects. The issues concerning those two aspects are related to their difficulties accessing lectures through the online system (See Table 3).

Table 3. Learners' engagement in the virtual learning environment using CLLA (An analysis of results inspired by Lee et al., 2019 model)

\begin{tabular}{|c|c|c|c|c|}
\hline & Factors & $\begin{array}{l}\text { Observed Items } \\
\text { Number }\end{array}$ & Yes $(\%)$ & No $(\%)$ \\
\hline \multirow{2}{*}{ 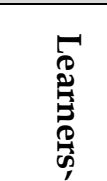 } & Psychological motivation & 6 & 47.78 & 52.22 \\
\hline & Peer collaboration & 5 & 81.84 & 18.16 \\
\hline \multirow{6}{*}{ 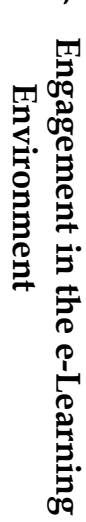 } & Cognitive problem solving & 5 & 69.24 & 30.76 \\
\hline & Interactions with instructors & 2 & 72.35 & 27.65 \\
\hline & Community support & 3 & 59.47 & 40.53 \\
\hline & Learning management & 4 & 79.22 & 20.78 \\
\hline & Total & 25 & 409.86 & 190.14 \\
\hline & $\begin{array}{l}\text { Average (Among } \\
\text { participants) }\end{array}$ & & 68.31 & 31.69 \\
\hline
\end{tabular}

\subsection{ILL Intervention Process}

In this study, ILL was employed to comprehend the whole target materials topics, namely building and traditional ceremony with "Joglo House", "Kraton (Palace)", "Benteng Vredeburg" (Vredeburg Fort), "Sonobudoyo Museum", "Mitoni (Seven Months of Pregnancy)", "Tedhak Siten (the first time of a Baby's stepping on the Ground)", "Ruwatan (Name of a traditional ceremony to reject evil crime)" and "Labuhan (An offering ceremony to the ruler of the oceans)" as sub-topics. The FUN (finding, understanding, and naturally-discussing) stages were procedurally implemented to achieve learners' target language acquisition through the use of ILL acculturation. The seven sub-topics were intervened 
through FUN in groups of five and scored by the peers-group (peers assessment). The results were accumulated as the group's portfolio scores.

Table 4. Learners' ILL average achievement

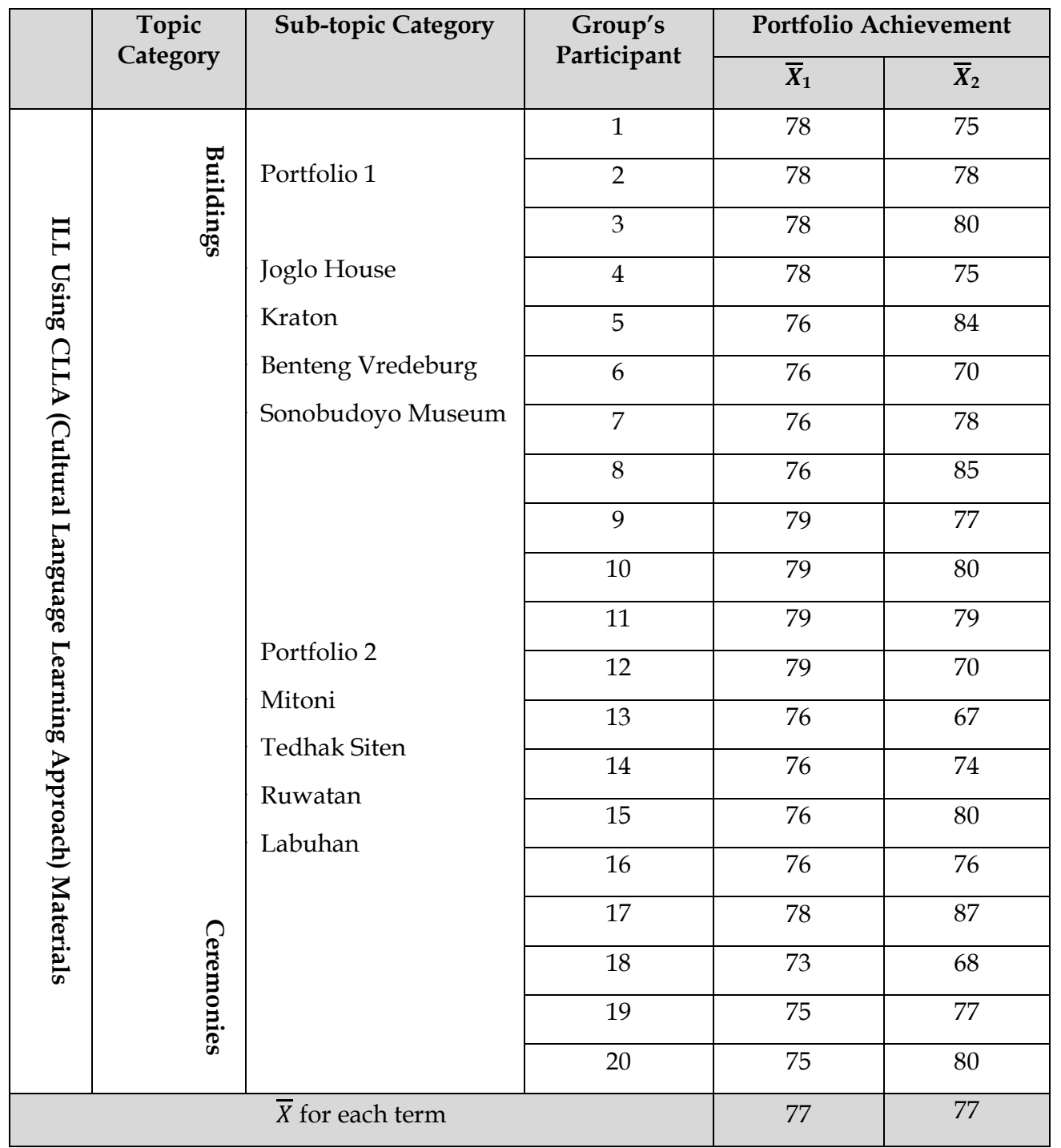

Referring to Sheppard's (2015) scoring rubrics, both scores include the "effective" category. By such findings, it is safe to mention that the two investigated variables were accomplished in this study. Firstly, it reflected the learners' wellacknowledged with CLLA as an approach to preserve traditional cultures through ILL acculturation. Secondly, it indicated their well-acculturated in using the target language in an integrated manner.

\section{Discussion}

This section elaborated the interpretation and implication concerning the two findings above which implied that the use of an approach in the ILL was intertwined and cannot be separated from one another. Previous studies revealed that an approach is possible to highlight the attempts for learners' 
learning enhancement quality (Beckwith, 1991; Trigwell et al., 1999; Rosário et al., 2013).

The current study revealed that there was not any significant difference among the four of six factors: "peer collaboration", "cognitive problem solving", "interaction with instructors", and "learning management" because of a set of parameters used for measuring the learners' engagement in the virtual learning environment. Concerning the use of CLLA, it was matched to carry out the ILL process. Even though it was found that the two factors of "psychological motivation" and "community support" have low percentages (that imply the low of the learners' psychological and community supports), it did not mean that it was due to the effect of using CLLA. Such a condition was experienced by most learners because of the lack of internet signals availability as the main means of online learning.

Another finding is related to the result of the ILL process. Previous studies asserted that ILL needs the learners' good understanding of the sources being learned, as using the language for communication must be automatically interwoven somewhat like a tapestry (Oxford, 2001; Orellana, 2001; Pardede, 2017). Oxford (ibid) proposes that to integrate the language skills instruction, teachers should consider the following stages: (1) Learning more about the various ways to integrate language skills in the classroom (e.g., content-based, task-based, or a combination); (2) Reflecting on their current approach and evaluate the extent to which the skills are integrated; (3) Choosing instructional materials, textbooks and technologies that promote the integration of listening, reading, speaking and writing as well as the associated skills of syntax, vocabulary and so on; (4) Integrating the other language skills through appropriate tasks; (5) Teaching language learning strategies and emphasizing that a given strategy can often enhance performance in multiple skills. This study has coincidentally considered such five stages as written above to carry out the learning process.

The current finding showed that intervened learners were well-acculturated in using the target language in an integrated manner. It is proved by the results of data analyses towards their learning achievement collected through a portfolio system consisting of two quasi-semesters that includes four sub-topics for each half-semester. It implied that CLLA was useful to acculturate learners' language learning in an interwoven manner, like a tapestry. Learners' acculturation in using integrated language using CLLA was also possible to cultivate their learning-centred strategy. Cultural representation contained in the learned discourses can also change the viewpoints of the language learners (Lustyantie \& Dewi, 2020). In this case, Loi et al. (2021) claimed that classroom instruction deployed more learner-centred activities and formative assessment to push the use of learning strategies.

\section{Conclusion}

This study was intended to acculturate the students of candidate teachers' ILL by using CLLA that was warranted appropriate use for such cases. It can be seen 
from the results of both the qualitative and quantitative data analyses that the understudied learners need to be well-acculturated in their ILL using CLLA. It is, therefore, recommended to use it as an alternative approach to ILL teaching practice. Besides, it can be also beneficial to instil noble moral values in students. Add to this, dindings showed that the average portfolio of assignments resulted in a 77 score, which includes an "effective" score (See Page 13).

Therefore, this applied research concluded that CLLA can be an alternative approach to acculturate learners' ILL acquisition, mainly to preserve traditional cultures. It is recommended for teachers, practitioners and language program designers to utilize CLLA as an approach in their language teaching programs. Such an approach should be used in the ILL setting for it was proved as an appropriate approach to acculturate students as the next young generation who have the responsibility to guard and preserve their native cultures. This must be realized and acculturated through ILL for the sake of preserving such valuable cultural heritages extinction.

\section{Limitations and Further Studies}

The limitation of the current study was that the ILL process which was carried out during the Covid-19 pandemic, since it affected most learners who have difficulty in adapting to the internet signal coverage. Such a condition influenced both the learners' psychological motivation and their community support during the learning process. Further studies should include an investigation on how to enhance the above two aspects by acculturating the use of CLLA with other topics for the sake of developing learners' ILL acquisition.

\section{Acknowledgements}

We acknowledge special thanks to all of the parties who supported this article publication.

\section{References}

Ann, F. V. S., \& Strong, G. (2002). Adult language learners: An overview. Harbour Press. https://www.tesol.org/docs/books/bk_CP_AdultLL_615

Bailey, K. M. (2005). Practical english language teaching speaking. McGraw-Hill.

Baimyrzaeva, M. (2018). Beginners' guide for applied research process: What is it, and why and how to do it? University of Central Asia: Graduate School of Development, 4, $1-43$.

Beckwith, J. B. (1991). Approaches to learning, their context and relationship to assessment performance. Higher Education, 22(1), 17-30. https://www.jstor.org/stable/3447151

Berry, J. W. (2003). Conceptual approaches to acculturation. American Psychological Association. https://doi.org/10.1037/10472-004

Berry, J. W. (2007). Acculturation strategies and adaptation. Queen's University. https://www.researchgate.net/publication/232564006_Acculturation_strategies _and_adaptation

Brown, H. D. (2007). Teaching by principles: An interactive approach to language pedagogy. Pearson Education, Inc.
Culatta,
R. (2020)
Andragogy
(Malcolm
Knowles).
https://www.instructionaldesign.org/theories/andragogy/ 
Dixson, M. D. (2015). Measuring student engagement in the online course: The online student engagement scale (OSE). Online Learning, 19(4), 51-65. https://doi.org/10.24059/olj.v19i4.561

Gautam, P. (2019). Integrated and segregated teaching of language skills: An exploration. Journal of NELTA Gandaki (JoNG), 1(1), 100-107.

Hermayawati. (2020). Cultural language learning approach (CLLA): An approach for language pedagogy. Universitas Mercu Buana Yogyakarta.

Jessel, J. (2020). Applied research (1st ed.). https://doi.org/10.1002/ 9781119171492.wecad058

Johnson, E. B., Ida, S., \& Ibnu, S. (2007). Contextual teaching and learning (Edisi Terjemahan). MLC.

Knowles, M. (1984a). Andragogy in action. Jossey-Bass.

Knowles, M. (1984b). Malcolm knowles, informal adult education, self-direction and andragogy. https://infed.org/mobi/malcolm-knowles-informal-adult-education-selfdirection-and-andragogy/

Knowles, M. (1984c). The adult learner: A neglected species (3rd ed.). Gulf Publishing.

Lee, J., Song, H., \& Hong, A. (2019). Exploring factors, and indicators for measuring students' sustainable engagement in e-learning. Department of Education, College of Education, Chung-Ang University.

Loi, N. Van, Thi, C., Hang, T., \& Tho, C. (2021). English proficiency gain and mediating factors in training: A self-evaluation of Vietnamese pre-service EFL teachers. International Journal of Learning, Teaching and Educational Research, 20(1), 22-47. https://doi.org/10.26803/ijlter.20.1.2

Lustyantie, N., \& Dewi, E. R. (2020). Representation of French culture as a foreign language through textbooks. International Journal of Learning, Teaching and Educational Research, 19(3), 404-421. https://doi.org/10.26803/ijlter.19.3.22

Makhlouf, J. (2019). Pedagogy vs. Andragogy: Where many get it wrong In their learning strategy. https://elmlearning.com/pedagogy-vs-andragogy/

Malamed, C. (2009). Characteristics of adult learners. https://theelearningcoach.com/learning/characteristics-of-adult-learners/

Marsaid. (2016). Islam dan kebudayaan: Wayang sebagai media pendidikan islam di nusantara. Kontemplasi, 4 , https://media.neliti.com/media/publications/67434-ID-islam-dan-kebudayaan -wayang-sebagai-medi.pdf

Marsiglia, F. F., Yabiku, S. T., Kulis, S., Nieri, T., Parsai, M., \& Becerra, D. (2011). The influence of linguistic acculturation and gender on the initiation of substance use among Mexican heritage preadolescents in the borderlands. The Journal of Early Adolescence, 31(2), 271-299. https:// doi.org/10.1177/0272431610363157

Newton-Rex, E. (2019). Six principles of applied research. Https://Medium.Com/. https://medium.com/on-coding/six-principles-of-applied-research875de3b44ba0

Orellana, E. por. (n.d.). The importance of integrating skills in the teaching of english as a foreign language. https://www.monografias.com/trabajos17/integratedskills/integrated-skills.shtml

Ostovar-Namaghi, S. A., \& Tajzad, M. (2014). Exploring EFL learners' perceptions of integrated skills approach: A grounded theory. English Language Teaching, 7(11), 92-98. https://doi.org/10.5539/elt.v7n11p92

Oxford, R. (2000). Integrating the language Skills. The Journal TESOL France, 5-12. https://www.tesol-france.org/

Pardede, P. (2017). Integrated skills approach in EFL classrooms: A literature review. UKI 
Press. https://eeduki.com/

Purwanto, S. (2018). Pendidikan nilai dalam pagelaran wayang kulit. Ta Allum Jurnal Pendidikan Islam, 6(1), 1-30. https:// doi.org/10.21274/taalum.2018.6.1.

Richards, J. C., \& Rodgers, T. S. (2001). Approaches and methods in language teaching. Cambridge University Press.

Rosário, P., Núñez, J. C., Ferrando, P. J., \& Al., E. (2013). The relationship between approaches to teaching and approaches to studying: a two-level structural equation model for biology achievement in high school. Metacognition Learning, 8, 47-77. https://doi.org/doi.org/10.1007/s11409-013-9095-6

Setiadi, H. (2017). Designing a supplementary reading using cultural Language learning approach (CLLA). International Journal for Innovation Education and Research (IJIER), 8(5), 111-128. https:// doi.org/10.31686/ijier.vol5.iss8.794

Sheppard, R. (2015). Rubrics for integrated assessment. https://blogs.newschool.edu/unchartedtesol

Stein, J., \& Graham, C. R. (2014a). Considerations for blended course designs. In M. Vai, $(E d)$, Essentials for blended learning: A standards-based guide. Routledge.

Stein, J., \& Graham, C. R. (2014b). What is Blended Learning? In M. Vai (Ed.), Essentials for blended learning: A standards-based guide. Routledge.

Trigwell, K., Waterhouse, F., \& Prosser, M. (1999). Relations between teachers' approaches to teaching and students' approaches to learning. Higher Education, 37(1), 57-70. https://doi.org/10.1023/A:1003548313194

UKEssays. (2018). History of english language teaching. https://www.ukessays.com/

Unesco. (2020). Browse the lists of intangible cultural heritage and the register of good safeguarding practices. Ich.Unesco.Org. https://ich.unesco.org/en/lists

Waters, A. (2012). Trends and issues in ELT methods and methodology. ELT Journal, 66(4), 440-449. https://doi.org/10.1093/elt/ccs038 